\title{
Chidamide combined with doxorubicin leads to synergistic anti-cancer effect and induces autophagy through inhibiting the PI3K/Akt/mTOR pathway in anaplastic thyroid carcinoma
}

\author{
Yishan $\mathrm{He}^{1}$, Xinguang Qiu ${ }^{2,}$ * \\ ${ }^{1}$ Department of Breast Surgery, the First Affiliated Hospital of Zhengzhou University, \\ Zhengzhou, China \\ ${ }^{2}$ Department of Thyroid Surgery, the First Affiliated Hospital of Zhengzhou \\ University, Zhengzhou, China
}

*Corresponding author: Xinguang Qiu, Email: Qiuxinguang2019@126.com. No. 1 Jianshe East Road, Zhengzhou 450052, Henan, PR China. Tel: +86037167967182.

\begin{abstract}
Anaplastic thyroid carcinoma (ATC) is a fatal malignant tumor, which belongs to the thyroid cancer with an overwhelmingly poor prognosis and eagerly demands effective systemic treatment strategies. We aimed to investigate the antitumor characteristics of Chidamide (CS055) in combination with doxorubicin (Dox) on ATC, and explore the underlying molecular mechanism. Herein, we found that CS055 and Dox inhibited proliferation, invasion and migration and promoted apoptosis of ATC cells. CS055 and Dox induced autophagic cell death (ADC) of ATC cell lines. And the expression of autophagy markers, BECN1, Atg5 and LC3-II was significantly enhanced in ATC cell lines treated with CS055 and Dox. Similarly, the in vivo study showed that CS055 and Dox administration significantly reduced tumor growth and induced tumor cell autophagy. Interestingly, the synergistic anti-cancer effect of CS055 in combination with doxorubicin was observed in vitro and in vivo. In addition, CS055 and Dox suppressed the proteins expression of $\mathrm{p}-\mathrm{P} 13 \mathrm{~K}, \mathrm{p}-\mathrm{AKT}$ and $\mathrm{mTOR}$ in vitro and in vivo and combination of CS055 and Dox exhibited greatest inhibitory effect. Taken together, our findings concluded that CS055 in combination with Dox exerted
\end{abstract}


antitumor activities and triggered autophogy in thyroid carcinoma probably through inhibiting the P13K/AKT/m/TOR signaling pathway.

Keywords: Anaplastic thyroid carcinoma; Chidamide; Doxorubicin; anti-cancer effect; autophagy

\section{Introduction}

Anaplastic thyroid carcinoma (ATC) is the a extremely biologically invasive neoplasm of malignant thyroid tumors with low incidence, rapidly disease progresses and low survival rate (Nagaiah et al., 2011). Because of its unstable genetic characteristics and complex genetic changes, the effective treatments have been lacking. Conventional methods such as surgical resection, radiotherapy and chemotherapy has no curative effect and cannot significantly improve the survival rate of patients, and it is particularly important to seek new treatment methods (Hallden and Portella 2012). At present, the biological treatment methods such as gene therapy, differentiation therapy, and protein inhibitor therapy are already in the exploratory stage (Fountzilas et al., 2017, Liu et al., 2018). Feasible induction of chemotherapy and radiotherapy sensitization often is applied in the comprehensive treatment therapy. The most commonly used chemotherapy drug for enhance the sensitization of chemoradiotherapy is doxorubicin (Dox), which was the only drug approved for anaplastic thyroid cancer treatment (Marano et al., 2017). Unfortunately, the valid time of doxorubicin efficacy is short, due to the resisting force to doxorubicin is rapidly formed once the treatment began (Wang et al., 2017). And the adverse effects of various chemotherapy drugs have resulted in insignificant clinical treatment, and the prognosis is poor. Therefore, the search for alternative drugs or drugs that enhance the sensitivity of chemotherapy drugs and reduce side effects is the direction for the future research.

HDAC inhibitor (HDACi) can selectively inhibit the activity of Histone deacetylase (HDAC) through binds to the catalytic region of HDAC, enhance the acetylation level of histones, loosen the chromatin condensation and restore the 
transcriptional activity. HDACi can blocks cell cycle, induce apoptosis, regulate autophagy, alter non-coding RNA expression, anti-angiogenesis, immune response, and effects on a variety of other cell signaling pathways to antitumor by altering epigenetic modification (Eckschlager et al., 2017). With the application of numerous HDACIs, its advantages of low toxicity, safety and broad antineoplastic spectrum have gradually been reflected, and it has become a major focus for the treatment of cancer.

Chidamide (CS055/ HBI-8000), a novel benzamide chemical type of HDACi, is currently being tested in many clinical trials in foreign and domestic country, which has been authorized to treat the cutaneous T-cell lymphoma and peripheral T-cell lymphoma in China (Gong et al., 2012). Studies have demonstrated that CS055 can lead solid tumors to apoptosis such as colon cancer (Liu et al., 2016), pancreatic cancer (Zhao and He 2015), non-small cell lung cancer (Zhou et al., 2014), hepatocellular carcinoma (Wang et al., 2012), even in other hematological tumors such as multiple myeloma (Xu et al., 2015), B-cell lymphoma (Lee and Kim 2012), leukemia cell line and primary cells (Gong et al. 2012) and leukemia stem cells (Li et al., 2015) have been certificated to promote apoptosis and induce cell cycle arrest. However, the effects and the mechanism of CS055 in anaplastic thyroid carcinoma have not been studied.

At present, drug combination therapy has become a hopeful therapeutic method for cancer treatment, specifically to drug resistant, and the synergistic effect of the two drugs helps to amplify weaker cell signals. Further, many studies have demonstrated that HDACIs could work in synergy to increase the antitumor activities of traditional chemotherapy drugs, of which included Vorinostat (SAHA), MS-275, Trichostatin A (TSA), and valproic acid (VPA) (Xie et al., 2010, Sung et al., 2011). The study of Zhang et al. (Zhang et al., 2017) has proved that there was a synergistic antitumor effect when used CS055 and Dox in combination with low dose concentration in peripheral T-cell lymphoma (PTCL). However, there is not relevant reports for the research of CS055 combined with Dox in ATC.

In this study, we explored the anti-tumor effect and possible mechanism of 
CS055, Dox or the combination of the two drugs in ATC cell lines and in vivo mice xenograft models. Our studies revealed anti-proliferation, anti-invasion, anti-migration and pro-apoptosis and inducing autophagy of CS055 and its synergistic effect with Dox, which might be involved in the P13K/AKT/mTOR pathway in ATC. Our findings provide a practical and theoretical basis for finding more effective treatments for anaplastic thyroid carcinoma.

\section{Results}

CS055 in combination with Dox synergistically inhibited cell proliferation and promoted apoptosis in ATC cell lines

Cell proliferation is one of the most striking features of Tumor cells activation. To test the effect of CS055 and Dox applied individually or in combination on ATC cell proliferation, FRO and 8505C were treated CS055 $(1 \mu \mathrm{M})$ or/and Dox $(0.5 \mu \mathrm{M})$ and then MTT assays were performed. Results showed that CS055 and Dox significantly restrained the proliferative activity of FRO and 8505C cells, and combination of CS055 and Dox had the strongest inhibitory effect (Figure 1A). Furthermore, as shown in Figure 1B, cell apoptosis analysis indicated that CS055 and Dox significantly induced cell apoptotic whether used respectively or in combination contrasted with the control. Combined treatment of CS055 and Dox resulted in highest percentage of apoptotic cells. These data suggest that combination of CS055 and Dox synergistically inhibits the proliferation and promotes apoptosis in ATC cells.

CS055 in combination with Dox synergistically suppressed invasion and migration of ATC cell lines

Next, we probed into the effect of CS055 and Dox on the invasion and migration of ATC cell lines. As shown in Figure 2A, CS055 and Dox significantly suppressed the invasion of FRO and $8505 \mathrm{C}$ cells whether used alone or in combination. Moreover, CS055 and Dox presented a plus capacity of inhibition on invasion of FRO and $8505 \mathrm{C}$ cells. The results from wound healing assay showed that the treatments of 
CS055 and Dox significantly decreased FRO and 8505C cell migration compared to the control group. And compared with the single drug effects, the combination group significantly suppressed the cells migration capacity (Figure 2B). These outcomes demonstrated that combination of CS055 and Dox can synergistically inhibit the invasion and migration abilities of ATC cells.

\section{CS055 in combination with Dox synergistically induced autophagy in ATC cells}

Autophagy, as another programmed cell death mode besides apoptosis, plays a significant role in maintaining the homeostasis of intracellular environment. As shown in Figure 3A, MDC staining (autophagic vacuoles) demonstrated that autolysosomes were highly accumulated in FRO and 8505C cells exposed to CS055 or Dox. The morphological characteristics demonstrated that autophagy was activated in FRO and 8505C cells since tested with CS055 and Dox. Moreover, CS055 and Dox showed an additive effect on MDC recruitment to autophagosomes in the cytoplasm of FRO and 8505C cells. To further verify the autophagy in ATC cells was induced by CSO55 and Dox. The expression of BECN1, Atg5, LC3-I, and LC3-II proteins was detected by qRT-PCR and western blot assays. As shown in Figure 3B and 3C, indicated that the mRNA and protein expression levels of autophagy-related gene BECN1 (Atg6) and Atg5 were significantly up-regulated by CS055 and Dox treatment whether used alone or in combination and CS055 and Dox showed an additive effect. The transformation of the dissolvable form of LC3-I to the autophagic vesicle-associated form LC3-II is considered as a particular symbol of autophagosome formation. Results showed that CS055 and Dox significantly improved the proportion of LC3-II to LC3-I and CS055 and Dox showed an additive effect. These results indicate that CS055 works in synergy with Dox to activate autophagy of ATC cells.

\section{CS055 in combination with Dox synergistically inhibited 8505C xenograft} growth and induced autophagy in vivo

To validate the impact of CS055 and Dox in vivo, anaplastic thyroid carcinoma xenograft models were established by hypodermically injection of $8505 \mathrm{C}$ cells in nude mice. Figure 4A and 4B showed that CS055 and Dox significantly exerted inhibition of tumor growth, respectively. And CS055 in combination with Dox had 
significantly inhibitory effect on growth of xenograft compared to single drug effects. Furthermore, qRT-PCR and western blot analyses showed that CS055 and Dox significantly increase the proportion of LC3-II to LC3-I and enhanced the expression of BECN1 and ATG5 in 8505C cells xenograft tissues, and CS055 in combination with Dox had synergistical effect (Figure 4C and 4D). These results suggest that CS055 in combination with Dox synergistically inhibits ATC xenograft growth and induces autophagy in vivo.

\section{CS055 in combination with Dox synergistically inhibited the P13K/AKT/mTOR pathway in vitro and in vivo}

The P13K/AKT/mTOR signaling pathway is related to the administration of multiple cellular functions, containing proliferation, migration, cell growth, and autophagy (Sinclair et al., 2013, Abeyrathna and Su 2015). Western blot was applied to examine whether the $\mathrm{P} 13 \mathrm{~K} / \mathrm{AKT} / \mathrm{mTOR}$ signalling pathway was connected with the antitumor impact of CS055 and Dox on ATC cells and the xenograft models. As shown in Figure $5 \mathrm{~A}$ and $5 \mathrm{~B}$, the protein expression levels of p-P13K, p-AKT and mTOR were significantly down-regulated after CS055 and Dox treatment whether used alone or in combination. Furthermore, there was a statistically significant in the combination therapy group compared with the single drug treatment group, which indicated that CS055 works in synergy with Dox to inhibit the P13K/AKT/mTOR signaling pathway. These data conclude that CS055 combination with Dox exerted antitumor activities and triggered autophogy in ATC probably through inhibiting the P13K-AKT-m-TOR signaling pathway.

\section{Discussion}

Previous studies given evidence of the impacts of HDAC inhibitors in miscellaneous tumor cells in vitro and in vivo, which implied that HDACi is a promising new tactic for the therapy of cancers (Cappellacci et al., 2018). It has been widely shown that the anti-cancer effects of HDACi are mainly obtained through the following ways: inducing the generation of reactive oxygen species (ROS); inducing the growth arrest, differentiation and apoptosis of tumor cells; preventing angiogenesis and 
lymphangiogenesis; and preventing the invasion and migration of tumors (Suliman et al., 2012). Since then, the US FDA approved the clinical application of SAHA, which belongs to HDAC inhibitor, for CTCL therapy. This field of study then gets even hotter and inspires us to seek and design more available and effective HDAC inhibitors.

CS055, a histone deacetylase inhibitor developed and synthesized independently in China, is mainly targeted on subtypes 1, 2, 3 of class I HDAC and subtypes10 of class IIb HDAC, which can inhibit the cell cycle and induce cell apoptosis of tumors through epigenetic regulation mechanisms (Gong et al. 2012, Yao et al., 2013), restore the drug sensitivity of drug-resistant tumor cells and inhibit the metastasis and recurrence of tumors (Zhou et al. 2014, Gao et al., 2017). Studies have shown that when CS055 combined with gemcitabine acts on pancreatic cancer cells, it can synergistically enhance gemcitabine-induced cell growth arrest and apoptosis, and enhance the anti-tumor effect of gemcitabine (Qiao et al., 2013). In our study, we exploited the combination treatment of CS055 and Dox to test ATC cells for purpose of exploring the anti-tumor effect and potential mechanisms. Our results showed that CS055 and Dox induced apoptosis and inhibited proliferation in ATC cells. Moreover, the experimental results demonstrated that CS055 and Dox used in combination synergistically enhanced the antitumor effects on ATC cells.

The degradation of extracellular matrix (ECM) is the primary condition for breaking the barrier between inter-tissues and facilitating the migration of tumor cells across tissues. HDACi is reported to prevent the metastasis and infiltration of cancer cells by regulating the transcription and expression of metastasis-suppressing genes and metastasis-promoting genes (Pratap et al., 2010, Koshkina et al., 2011). Studies reported by Lin et al. have showed that CSO55 restrains the migration of lung cancer cells in a dose-dependent manner (Lin et al., 2016). Lu et al (Lu et al., 2018) found that combination of CS055 and Ganoderma in vitro inhibits proliferation, invasion and infiltration abilities of A375.S2 cells and induces a large number of apoptotic cells of A375.S2 cells with a dose dependent manner. Consistent with that, our results demonstrated that CS055 and Dox significantly suppressed the invasion and migration 
of FRO and 8505C cells and worked in synergy.

Autophagy, as an important mechanism for maintaining homeostasis of the internal environment, plays a significant role in the pathogenesis, progress, therapeutic strategies and metabolism of tumors, and can improve the sensitivity of thyroid cancer cells to chemoradiotherapy (Morani et al., 2014). A study has shown that the multiple tumor cell death caused by suberoylanilide hydroxamic acid (SAHA), a HDACi, is independent of caspase-activated apoptosis, but induces autophagic cell death through a large number of activated autophagy reactions, thus inhibiting the growth of tumor cells (Lee et al., 2012). HDACi can increase the formation of intracellular acidic vesicles, recruited LC3-II to autophagosomes, promote the expression of Beclin1 protein and decrease the expression of p62 (Gandesiri et al., 2012). Zhao et al (Zhao and He 2015) have reported that the autophagy of $\mathrm{Pa} \mathrm{Tu} 8988$ pancreatic cancer cells significantly increased after the treatment of CS055, which suggesting that CS055 can promote pancreatic tumor cell death by inducing autophagy. In this study, CS055 and Dox significantly repressed the growth of the tumor whether used alone or in combination. Moreover, CS055 and Dox induced autophagic vacuoles and increased the expression levels of BECN1, Atg5 and ratio of LC3-II to LC3- $\square$ in vitro and in vivo study and there was a synergistically effect in the combination treatment group compared with the single drug group, which confirmed that the autophagic process seems to be another probably mechanism to induce cancer cell death treated with CS055 and Dox in ATC tumor.

Studies have shown that $\mathrm{P} 13 \mathrm{~K} / \mathrm{AKT} / \mathrm{m} / \mathrm{TOR}$ signaling pathway is closely related to the occurrence and development of human tumors, which plays a significant role in malignant proliferation, metastasis, apoptosis, invasion and autophagy and other functions of tumor cells (Guan et al., 2007, Zhang et al., 2011, Xie et al., 2013). Therefore, PI3K-Akt-mTOR signaling pathway is expected to become a new target for the treatment of malignant tumors. Study presented by Tam-burrino et al. (Tamburrino et al., 2012) has demonstrated that the PI3K/Akt/mTOR signaling pathway was over-activated in the occurrence and progression of thyroid cancer. Therefore, targeting this pathway can effectively inhibit the proliferation of ATC cell 
lines. Moreover, HDACi can down-regulating the P13K/AKT/m/TOR signaling pathway and inducing apoptosis and autophagy (Chiao et al., 2013, Foster et al., 2014). Encouraged from the previous studies mentioned above, we tested the expression of proteins involved in P13K/AKT/m/TOR signaling pathway in ATC cells or xenograft nude mice. As indicated in our western blot results, the protein expression levels of p-P13K, p-AKT and mTOR were significantly down-regulated after CS055 and Dox treatment whether used alone or in combination, and more significantly, the decrease in the combination treatment group was statistically significant compared with that in the single drug groups, suggesting that CS055 and Dox inhibit the ATC tumor probably through inhibiting the P13K/AKT/m/TOR signaling pathways.

\section{Conclusion}

In conclusion, in vitro and in vivo experiments shown that the combination treatment with CS055 and doxorubicin can synergistic inhibited the proliferation, invasion and migration and induced apoptosis and autophagy of ATC cells, all of which probably through inhibiting the $\mathrm{P} 13 \mathrm{~K} / \mathrm{AKT} / \mathrm{m} / \mathrm{TOR}$ signaling pathways. These suggest that CS055 combination with doxorubicin may be a promising clinical therapeutic regimen for the anaplastic thyroid carcinoma, which might shed new light on anaplastic thyroid carcinoma therapy.

\section{Materials and methods}

\section{Cell lines and cell culture}

The human anaplastic thyroid carcinoma cell lines FRO and 8505C were afforded by Biological Cell Bank of Shanghai Academy of Chinese Sciences. The cell lines were cultured in RPMI-1640 (GIBCO. Uxbridge, UK) comprised of 10\% fetal bovine serum (FBS; GIBCO) and 1\% penicillin /streptomycin (GIBCO). All cells were maintained in a humid atmosphere containing $5 \% \mathrm{CO}_{2}$ at $37^{\circ} \mathrm{C}$.

\section{Assessment of cell proliferative viability by MTT assay}

Briefly, cells $\left(2 \times 10^{3}\right.$ cells/well) were cultured in triplicate in 96-well plates in the presence or absence of CS055 (Shenzhen Chipscreen Biosciences Ltd, Shenzhen, 
China) and Dox (Sigma, St. Louis, MO, USA) with the final volume of $100 \mu$ l. After treatment for the indicated times (0, 1, 2, 3 days), $10 \mathrm{uL}$ of MTT (Sigma) $(5 \mathrm{mg} / \mathrm{mL})$ was added to each well with that incubation time for $4 \mathrm{~h}$ at $37^{\circ} \mathrm{C}$.Then we removed the supernatant discreetly, added $100 \mu \mathrm{L}$ DMSO to each well, shaken the plate until the crystals were dissolved compliantly. Finally, the absorbance was evaluated in Varioskan $^{\mathrm{TM}}$ LUX Multi-function microplate reader (Thermo Scientific, USA) at a wavelength of $490 \mathrm{~nm}$. The reported data derived from three separate experiments.

\section{Detection of apoptosis by flow cytometry analysis}

In the study, we used the An Annexin-V-fluorescein isothiocyanate (FITC) Apoptosis Detection Kit (BD Biosciences, USA) to detect the cells apoptosis using flow cytometry. Cells were seeded with the density of $2 \times 10^{5}$ cells/well in six-well plates and treated with CS055 and Dox. After incubation for 48h, the cells were gathered and the cell suspension was coordinate to $1 \times 10^{6} \mathrm{cell} / \mathrm{ml}$. The apoptosis of FRO and 8505C cell lines was monitored via Annexin V-FITC/propidium iodide (PI) double staining. Finally, the treated cells were analyzed in a Beckman Gallios flow cytometer. All experiments were implemented in triplicate.

\section{Invasion and migration assays}

Cell invasion assays were implemented in 24-well plates with Costar Transwell with $6.5 \mathrm{~mm}$ diameter and $5 \mathrm{~mm}$ pores (Corning Costar Corp., NY, USA). Cells were seeded in the superstratum chamber of Boyden compartments at a density of $5 \times 10^{4}$ cells/well with serum free media containing CS055 and Dox individually or together. The substratum chamber was contained with $600 \mu \mathrm{L}$ of $0.2 \%$ BSA-supplemented RPMI-1640 medium for $24 \mathrm{~h}$ at $37{ }^{\circ} \mathrm{C}$ and $5 \% \mathrm{CO}_{2}$, followed by immobilization and dyeing by the use of crystal violet $(0.1 \%)$. The invaded cells were photographed.

Cell migration was detected by wound healing assay. Cells were clutured in the 6-well plates at $2 \times 10^{5}$ cells/well in RPMI-1640 complemented with $10 \%$ FBS and grown to $75-85 \%$ confluency. The sterile micropipette spear was used to eradicate the single-deck cells and the plates were washed with PBS. Then, the culture solution was substituted by free-serum. The migration ability was detected and imaged after 0 or 24 $\mathrm{h}$ of incubation under the inverted microscope (Olympus IX51, Tokyo, Japan). The 
migration rate of ATC cells was analyzed using ImageJ software (National Institutes of Health, MD, USA).

\section{RNA extraction and Quantitative reverse-transcriptase polymerase chain reaction (qRT-PCR)}

Total RNA of the ATC cell lines and mice tumor tissue was extracted according to the RNA $^{\text {iso }}$ TM Plus kit instruction manual, of which then used as the template for first-strand cDNA synthesis. qPCR was performed on a LightCycler 480 II (Roche Diagnostic Ltd., Basel, Switzerland) with RealStar Green Power Mixture (GenStar Biosolutions Co., Lt ., Beijing, China) according to the manufacturers' instructions. Gene expression level was computed by the following the equation: relative gene expression $=2^{-(\operatorname{treated}(\triangle \mathrm{GENE}-\triangle \mathrm{GAPDH})-\operatorname{control}(\triangle \mathrm{GENE}-\triangle \mathrm{GAPDH}))} . G A P D H$ was used as the endogenous control to standardize mRNA content. Each swatch was experiment in triplicate.

\section{Western blot analysis}

The treated ATC cells and nude mice tumor tissues were collected and dissociated with RIPA lysis buffer. The total protein lysates were extracted and protein concentrations were caculated by Bicinchoninic acid (BCA) assay. The equal protein specimens were separated by SDS-PAGE and then electro-transferred onto the nitrocellulose membrane. Membranes were blocked for $30 \mathrm{~min}$ and incubated with specific antibodies (against BECN1, Atg5, LC3- $\square / \mathrm{LC} 3-\square, \mathrm{P} 13 \mathrm{~K}, \mathrm{p}-\mathrm{P} 13 \mathrm{~K}$, AKT, p-AKT, mTOR, and $\beta$-actin) overnight at $4^{\circ} \mathrm{C}$ following hatch with secondary antibodies for $2 \mathrm{~h}$. Protein signals were imagined by ECL detection reagents according to manufacturer's instruction using a ChemiDoc XRS system (Bio rad, Hercules, CA, USA). ALL specific antibodies were obtained from Cell Signaling Biotechnology (Danvers, MA, USA).

\section{MDC incorporation assay}

Cells at a density of $2 \times 10^{5}$ cells/well were cultured in a 6-well plate and incubated with the indicated drug treatment for $48 \mathrm{~h}$. After washing with cold PBS, autophagic vacuoles were then stained with $0.05 \mathrm{mM}$ monodansylcadaverine (MDC), which was an autofluorescent base with the capacity of backlogging in autophagic vacuoles, at 
indoor temperature for $30 \mathrm{~min}$. After incubation, cells were imagined using a Laser confocal fluorescence microscope at 600X magnification (Olympus IX70, Tokyo, Japan).

\section{In vivo experiment}

Forty BALB/c nude mice at the age of 5 weeks (18-22 g) were offered by the Animal Center of the Chinese Academy of Sciences. Experiments were approved by Animal Experimentation Ethics Committees of the First Affiliated Hospital of Zhengzhou University. $8505 \mathrm{C}$ cells $\left(2 \times 10^{7} / 200 \mu \mathrm{l} /\right.$ mouse $)$ were suspended in PBS and hypodermically injected into the flank of the nude mouse to establish the anaplastic thyroid carcinoma mouse model. Mouse with approximately similar tumor size were stochastically separated into 4 treatment groups $(n=10)$ : control (vehicle), CS055 (12.5 mg/kg/day), Dox (3 mg/kg/day) and (CS055 $12.5 \mathrm{mg} / \mathrm{kg}+$ Dox $3 \mathrm{mg} / \mathrm{kg} / \mathrm{d})$ groups and were given through intraperitoneal (ip) once a day consecutively for 30 days. Tumors were gauged every five days. The tumor volumes were measured and calculated with the following formula: volume $\left(\mathrm{mm}^{3}\right)=\left(\right.$ width $\times$ width $\left.{ }^{2}\right) / 2$. After 30 days, the treated mice were euthanized and the tumors were collected and examined.

\section{Statistical analysis}

Data were analyzed using statistical software SPSS 18.0. All values were presented as the mean $\pm \mathrm{SD}$ and the statistical analyses were implemented via the Student's $t$-test. And p-values $<0.05$ was considered as statistically significant.

\section{Acknowledgements}

No.

Declaration of competing interest

No potential conflicts of interest were disclosed.

\section{References}

Abeyrathna, P. and Su, Y. (2015). The critical role of Akt in cardiovascular function. Vascul Pharmacol 74, 38-48.

Cappellacci, L., Perinelli, D. R., Maggi, F., Grifantini, M. and Petrelli, R. (2018). Recent Progress in Histone Deacetylase Inhibitors as Anticancer Agents. Curr Med Chem.

Chiao, M. T., Cheng, W. Y., Yang, Y. C., Shen, C. C. and Ko, J. L. (2013). Suberoylanilide 
hydroxamic acid (SAHA) causes tumor growth slowdown and triggers autophagy in glioblastoma stem cells. Autophagy 9, 1509-1526.

Eckschlager, T., PIch, J., Stiborova, M. and Hrabeta, J. (2017). Histone Deacetylase Inhibitors as Anticancer Drugs. Int $J$ Mol Sci 18.

Foster, K. A., Jane, E. P., Premkumar, D. R., Morales, A. and Pollack, I. F. (2014). Co-administration of ABT-737 and SAHA induces apoptosis, mediated by Noxa upregulation, Bax activation and mitochondrial dysfunction in PTEN-intact malignant human glioma cell lines. J Neurooncol 120, 459-472.

Fountzilas, C., Patel, S. and Mahalingam, D. (2017). Review: Oncolytic virotherapy, updates and future directions. Oncotarget 8, 102617-102639.

Gandesiri, M., Chakilam, S., Ivanovska, J., Benderska, N., Ocker, M., Di Fazio, P., Feoktistova, M., Gali-Muhtasib, H., Rave-Frank, M., Prante, O., Christiansen, H., Leverkus, M., Hartmann, A. and Schneider-Stock, R. (2012). DAPK plays an important role in panobinostat-induced autophagy and commits cells to apoptosis under autophagy deficient conditions. Apoptosis 17, 1300-1315.

Gao, S., Li, X., Zang, J., Xu, W. and Zhang, Y. (2017). Preclinical and Clinical Studies of Chidamide (CS055/HBI-8000), An Orally Available Subtype-selective HDAC Inhibitor for Cancer Therapy. Anticancer Agents Med Chem 17, 802-812.

Gong, K., Xie, J., Yi, H. and Li, W. (2012). CS055 (Chidamide/HBI-8000), a novel histone deacetylase inhibitor, induces G1 arrest, ROS-dependent apoptosis and differentiation in human leukaemia cells. Biochem $J$ 443, 735-746.

Guan, Z., Wang, X. R., Zhu, X. F., Huang, X. F., Xu, J., Wang, L. H., Wan, X. B., Long, Z. J., Liu, J. N., Feng, G. K., Huang, W., Zeng, Y. X., Chen, F. J. and Liu, Q. (2007). Aurora-A, a negative prognostic marker, increases migration and decreases radiosensitivity in cancer cells. Cancer Res 67, 10436-10444.

Hallden, G. and Portella, G. (2012). Oncolytic virotherapy with modified adenoviruses and novel therapeutic targets. Expert Opin Ther Targets 16, 945-958.

Koshkina, N. V., Rao-Bindal, K. and Kleinerman, E. S. (2011). Effect of the histone deacetylase inhibitor SNDX-275 on Fas signaling in osteosarcoma cells and the feasibility of its topical application for the treatment of osteosarcoma lung metastases. Cancer 117, 3457-3467.

Lee, H. M. and Kim, K. S. (2012). Observable structures of small neutral and anionic gold clusters. Chemistry 18, 13203-13207.

Lee, Y. J., Won, A. J., Lee, J., Jung, J. H., Yoon, S., Lee, B. M. and Kim, H. S. (2012). Molecular mechanism of SAHA on regulation of autophagic cell death in tamoxifen-resistant MCF-7 breast cancer cells. Int J Med Sci 9, 881-893.

Li, Y., Chen, K., Zhou, Y., Xiao, Y., Deng, M., Jiang, Z., Ye, W., Wang, X., Wei, X., Li, J., Liang, J., Zheng, Z., Yao, Y., Wang, W., Li, P. and Xu, B. (2015). A New Strategy to Target Acute Myeloid Leukemia Stem and Progenitor Cells Using Chidamide, a Histone Deacetylase Inhibitor. Curr Cancer Drug Targets 15, 493-503.

Lin, S. H., Wang, B. Y., Lin, C. H., Chien, P. J., Wu, Y. F., Ko, J. L. and Chen, J. J. (2016). Chidamide alleviates TGF-beta-induced epithelial-mesenchymal transition in lung cancer cell lines. Mol Biol Rep 43, 687-695.

Liu, F., Xu, K., Yang, H., Li, Y., Liu, J., Wang, J. and Guan, Z. (2018). A novel approach to 
glioma therapy using an oncolytic adenovirus with two specific promoters. Oncol Lett 15, 3362-3368.

Liu, L., Qiu, S., Liu, Y., Liu, Z., Zheng, Y., Su, X., Chen, B. and Chen, H. (2016). Chidamide and 5 -flurouracil show a synergistic antitumor effect on human colon cancer xenografts in nude mice. Neoplasma 63, 193-200.

Lu, C. T., Leong, P. Y., Hou, T. Y., Huang, S. J., Hsiao, Y. P. and Ko, J. L. (2018). Ganoderma immunomodulatory protein and chidamide down-regulate integrin-related signaling pathway result in migration inhibition and apoptosis induction. Phytomedicine 51, 39-47.

Marano, F., Frairia, R., Rinella, L., Argenziano, M., Bussolati, B., Grange, C., Mastrocola, R., Castellano, I., Berta, L., Cavalli, R. and Catalano, M. G. (2017). Combining doxorubicin-nanobubbles and shockwaves for anaplastic thyroid cancer treatment: preclinical study in a xenograft mouse model. Endocr Relat Cancer 24, 275-286.

Morani, F., Titone, R., Pagano, L., Galetto, A., Alabiso, O., Aimaretti, G. and Isidoro, C. (2014). Autophagy and thyroid carcinogenesis: genetic and epigenetic links. Endocr Relat Cancer 21, R13-29.

Nagaiah, G., Hossain, A., Mooney, C. J., Parmentier, J. and Remick, S. C. (2011). Anaplastic thyroid cancer: a review of epidemiology, pathogenesis, and treatment. $J$ Oncol 2011, 542358.

Pratap, J., Akech, J., Wixted, J. J., Szabo, G., Hussain, S., McGee-Lawrence, M. E., Li, X., Bedard, K., Dhillon, R. J., van Wijnen, A. J., Stein, J. L., Stein, G. S., Westendorf, J. J. and Lian, J. B. (2010). The histone deacetylase inhibitor, vorinostat, reduces tumor growth at the metastatic bone site and associated osteolysis, but promotes normal bone loss. Mol Cancer Ther 9, 3210-3220.

Qiao, Z., Ren, S., Li, W., Wang, X., He, M., Guo, Y., Sun, L., He, Y., Ge, Y. and Yu, Q. (2013). Chidamide, a novel histone deacetylase inhibitor, synergistically enhances gemcitabine cytotoxicity in pancreatic cancer cells. Biochem Biophys Res Commun 434, 95-101.

Sinclair, A., Latif, A. L. and Holyoake, T. L. (2013). Targeting survival pathways in chronic myeloid leukaemia stem cells. Br J Pharmacol 169, 1693-1707.

Suliman, B. A., Xu, D. and Williams, B. R. (2012). HDACi: molecular mechanisms and therapeutic implications in the innate immune system. Immunol Cell Biol 90, 23-32.

Sung, V., Richard, N., Brady, H., Maier, A., Kelter, G. and Heise, C. (2011). Histone deacetylase inhibitor MGCD0103 synergizes with gemcitabine in human pancreatic cells. Cancer Sci 102, 1201-1207.

Tamburrino, A., Molinolo, A. A., Salerno, P., Chernock, R. D., Raffeld, M., Xi, L., Gutkind, J. S., Moley, J. F., Wells, S. A., Jr. and Santoro, M. (2012). Activation of the mTOR pathway in primary medullary thyroid carcinoma and lymph node metastases. Clin Cancer Res 18, 3532-3540.

Wang, H., Guo, Y., Fu, M., Liang, X., Zhang, X., Wang, R., Lin, C. and Qian, H. (2012). Antitumor activity of Chidamide in hepatocellular carcinoma cell lines. Mol Med Rep $\mathbf{5}$, 1503-1508.

Wang, W., Zhou, J., Zhao, L. and Chen, S. (2017). Combination of SL327 and Sunitinib Malate leads to an additive anti-cancer effect in doxorubicin resistant thyroid carcinoma cells. Biomed Pharmacother 88, 985-990. 
Xie, B., Zhou, J., Shu, G., Liu, D. C., Zhou, J., Chen, J. and Yuan, L. (2013). Restoration of klotho gene expression induces apoptosis and autophagy in gastric cancer cells: tumor suppressive role of klotho in gastric cancer. Cancer Cell Int 13, 18.

Xie, C., Edwards, H., Xu, X., Zhou, H., Buck, S. A., Stout, M. L., Yu, Q., Rubnitz, J. E., Matherly, L. H., Taub, J. W. and Ge, Y. (2010). Mechanisms of synergistic antileukemic interactions between valproic acid and cytarabine in pediatric acute myeloid leukemia. Clin Cancer Res 16, 5499-5510.

Xu, L., Tang, H. L., Gong, X., Xin, X. L., Dong, Y., Gao, G. X., Shu, M. M. and Chen, X. Q. (2015). [Inducing effect of chidamide on apoptosis of multiple myeloma cells and its relerance to DNA damage response]. Zhongguo Shi Yan Xue Ye Xue Za Zhi 23, 450-454.

Yao, Y., Zhou, J., Wang, L., Gao, X., Ning, Q., Jiang, M., Wang, J., Wang, L. and Yu, L. (2013). Increased PRAME-specific CTL killing of acute myeloid leukemia cells by either a novel histone deacetylase inhibitor chidamide alone or combined treatment with decitabine. PLoS One 8, e70522.

Zhang, H., Dong, L., Chen, Q., Kong, L., Meng, B., Wang, H., Fu, K., Wang, X., Pan-Hammarstrom, Q., Wang, P. and Wang, X. (2017). Synergistic antitumor effect of histone deacetylase inhibitor and Doxorubicin in peripheral T-cell lymphoma. Leuk Res 56, 29-35.

Zhang, L., Sun, S., Zhou, J., Liu, J., Lv, J. H., Yu, X. Q., Li, C., Gong, L., Yan, Q., Deng, M., Xiao, L., Ma, H., Liu, J. P., Peng, Y. L., Wang, D., Liao, G. P., Zou, L. J., Liu, W. B., Xiao, Y. M. and Li, D. W. (2011). Knockdown of Akt1 promotes Akt2 upregulation and resistance to oxidative-stress-induced apoptosis through control of multiple signaling pathways. Antioxid Redox Signal 15, 1-17.

Zhao, B. and He, T. (2015). Chidamide, a histone deacetylase inhibitor, functions as a tumor inhibitor by modulating the ratio of Bax/Bcl-2 and P21 in pancreatic cancer. Oncol Rep 33, 304-310.

Zhou, Y., Pan, D. S., Shan, S., Zhu, J. Z., Zhang, K., Yue, X. P., Nie, L. P., Wan, J., Lu, X. P., Zhang, W. and Ning, Z. Q. (2014). Non-toxic dose chidamide synergistically enhances platinum-induced DNA damage responses and apoptosis in Non-Small-Cell lung cancer cells. Biomed Pharmacother 68, 483-491.

\section{Figure legends}

Figure 1. The effects of CS055 and Dox applied individually or in combination on cell proliferation and apoptosis of FRO and 8505C cells. A. FRO and 8505C cells were treated with CS055 $(1 \mu \mathrm{M})$ and Dox $(0.5 \mu \mathrm{M})$ for indicated times $(0,1,2,3$ days $)$ and the proliferative activity was measured by MTT assays. B. The treated FRO and 8505C cells were subjected to Annexin-V/PI staining with CS055 and Dox alone or in combination at indicated concentrations at $48 \mathrm{~h}$ and cells apoptosis was determined by 
flow cytometry. ${ }^{*} P<0.05$ vs. the control group; ${ }^{\#} P<0.05$ vs CS055-treated group; ${ }^{\S} P<0.05$ vs. Dox-treated group.

Figure 2. Cell invasion and migration were induced by CS055 and Dox applied individually or in combination in FRO and $8505 \mathrm{C}$ cell lines at $48 \mathrm{~h}$. A. The cells invasion ability was determined with Transwells assay. B. The cells migration capacity was detected by wound healing assay at 0 and $48 \mathrm{~h}$. $* P<0.05$ vs. the control group; ${ }^{\#} P<0.05$ vs CS055-treated group; ${ }^{\S} P<0.05 v s$. Dox-treated group.

Figure 3. Cell autophagy induced by single CS055 or in combination with Dox in FRO and $8505 \mathrm{C}$ cell lines. A. Visualization of intracellular autophagic vacuoles in the FRO and 8505C cells after treatment with CS055, Dox, or CS055 and Dox in combination by MDC staining. FRO and 8505C cells after treatment with CS055, Dox, or CS055 and Dox in combination. Magnification $\times 200$. B. The quantitative analysis of autophagy-related genes BECN1 and Atg5 expression in the FRO and 8505C cells by qPCR analysis. C. The expression of autophagy-related proteins BECN1, Atg5 and LC3-I/ LC3-II by western blot analysis. $* P<0.05$ vs. the control group; ${ }^{\#} P<0.05$ vs CS055-treated group; ${ }^{\S} P<0.05$ vs. Dox-treated group.

Figure 4. Effect of single CS055 and combination with Dox on the growth of ATC xenograft growth. A. Tumor volumes after CS055 (12.5 mg/kg/day) and Dox (3 $\mathrm{mg} / \mathrm{kg} /$ day) alone or in combination treatment were indicated. B. Tumor weight was calculated. C. The quantitative investigation of BECN1 and Atg5 expression in tumor tissues of nude mice by qRT-PCR analysis. D. The protein expression of BECN1, Atg5 and LC3-I/ LC3-II in tumor tissues of nude mice by western blot. $* P<0.05$ vs. the control group; ${ }^{\#} P<0.05$ vs CS055-treated group; ${ }^{\S} P<0.05$ vs. Dox-treated group.

Figure 5. Effect of single CS055 and combination with Dox on P13K/AKT/m/TOR signaling pathway in vitro and in vivo. A and B. The protein expression of related P13K/AKT/m-TOR pathway was detected by western blot in FRO and 8505C cells and xenograft tissues with CS055 and Dox treatment whether used alone or in combination. ${ }^{*} P<0.05$ vs. the control group; ${ }^{\#} P<0.05$ vs CS055-treated group; ${ }^{\S} P<$ 0.05 vs. Dox-treated group. 
A

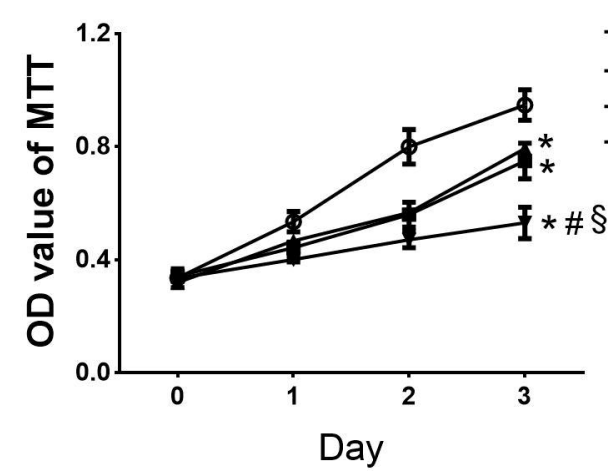

B

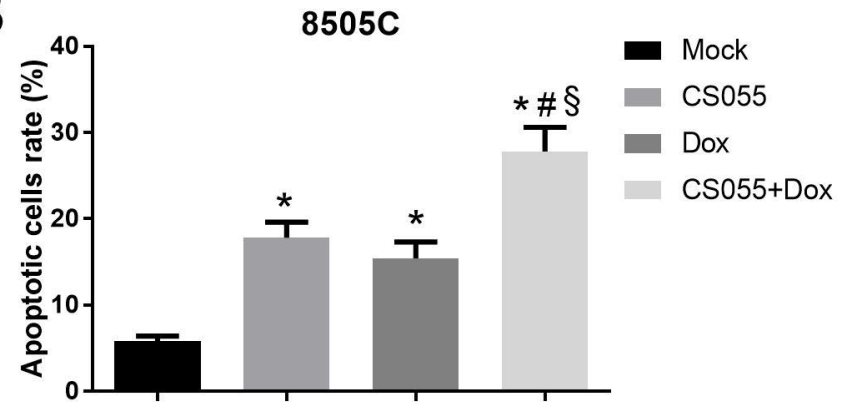

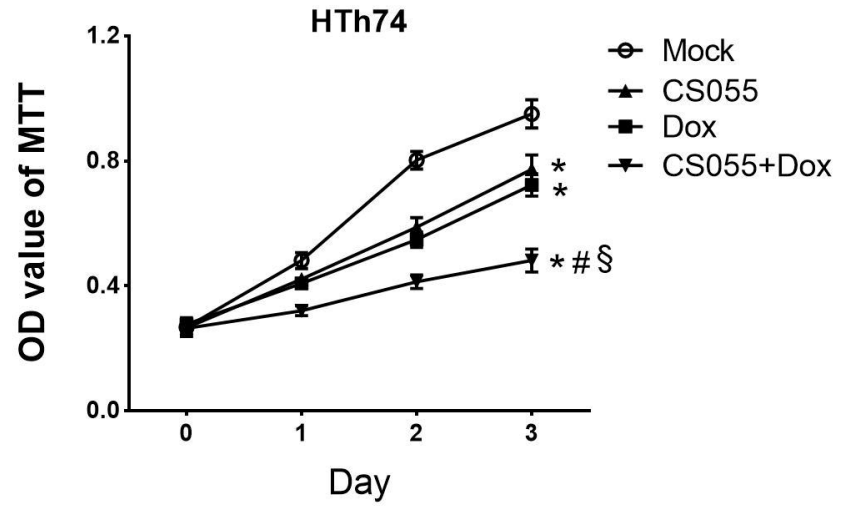

HTh74

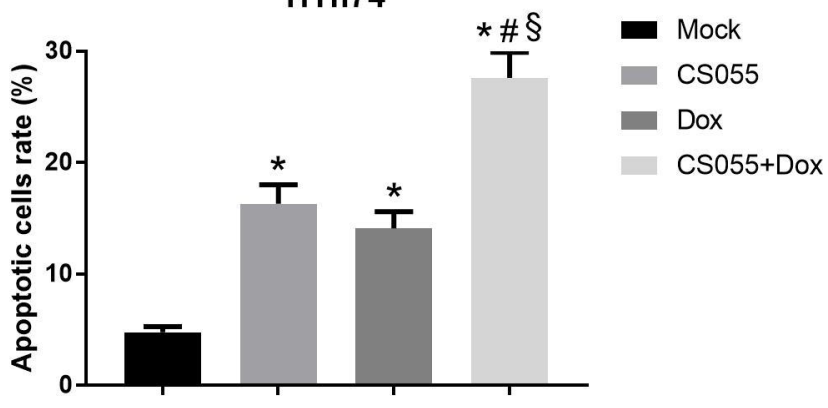


A Mock

CS055

DOX

CS055+DOX

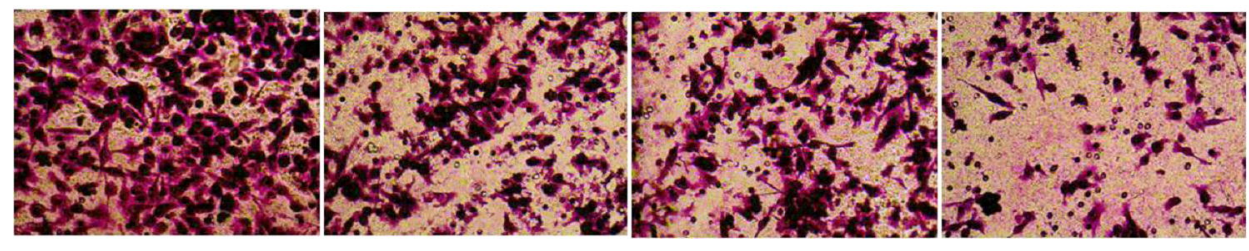

$8505 \mathrm{C}$

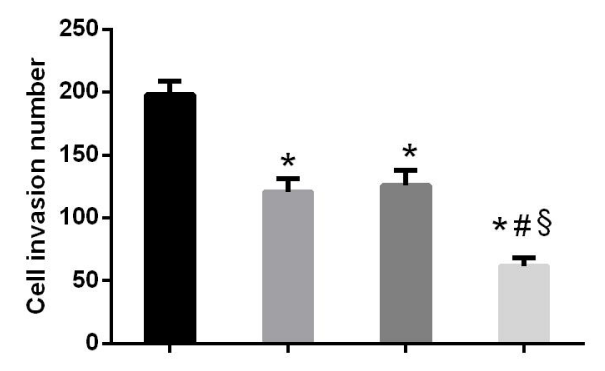

- Mock

CS055

Dox

CS055+Dox

Dox cs055+Dox

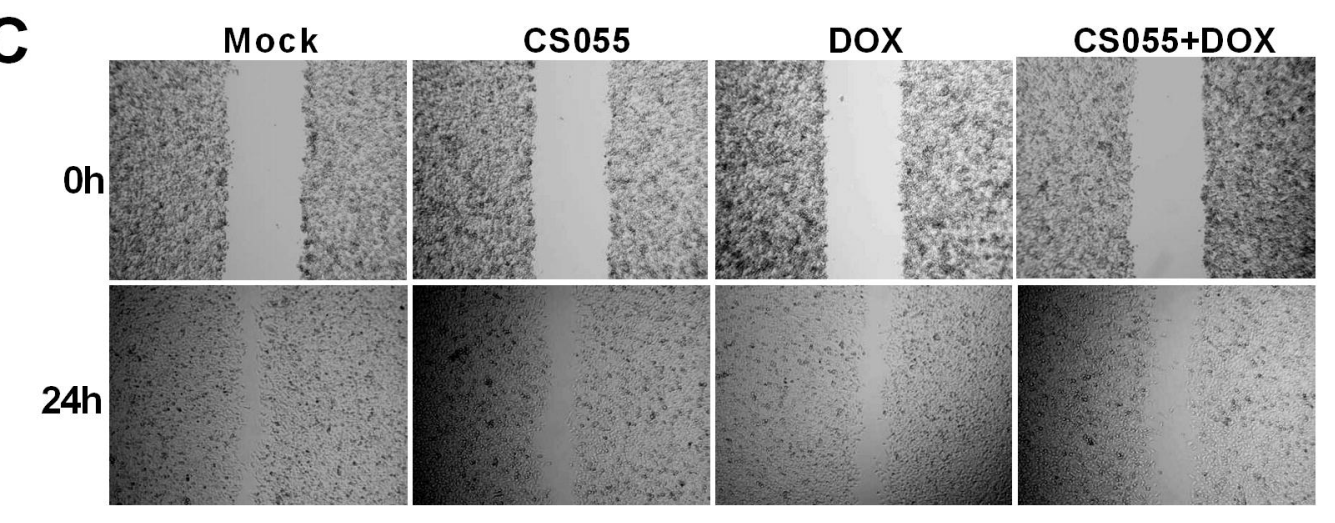

$8505 \mathrm{C}$

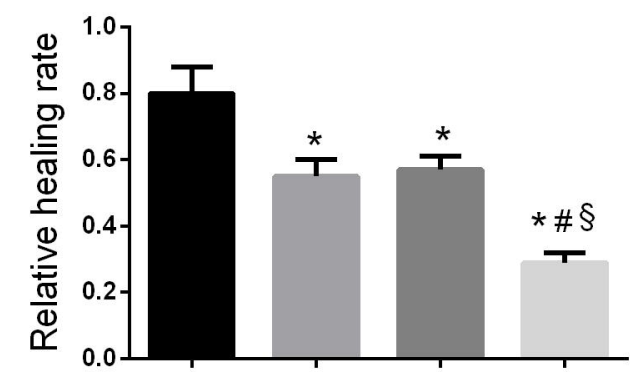

B

Mock

CS055

DOX

CS055+DOX

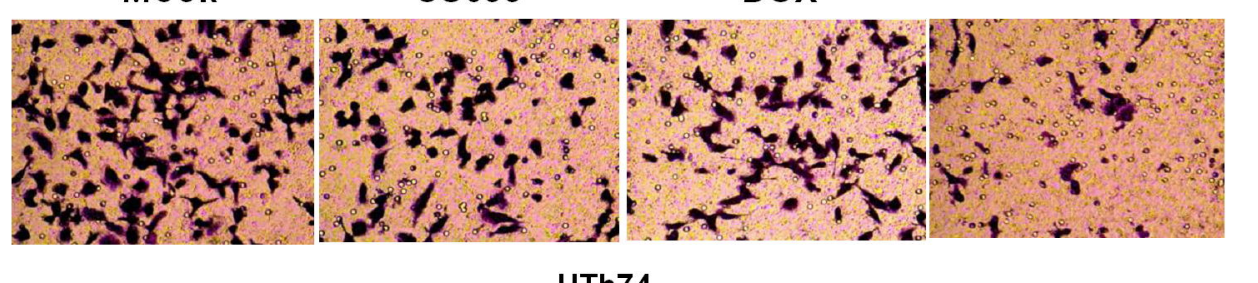
HTh74

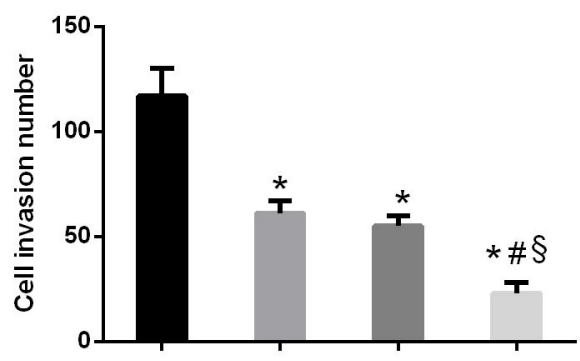

- Mock

CS055

Dox

CS055+Dox

D

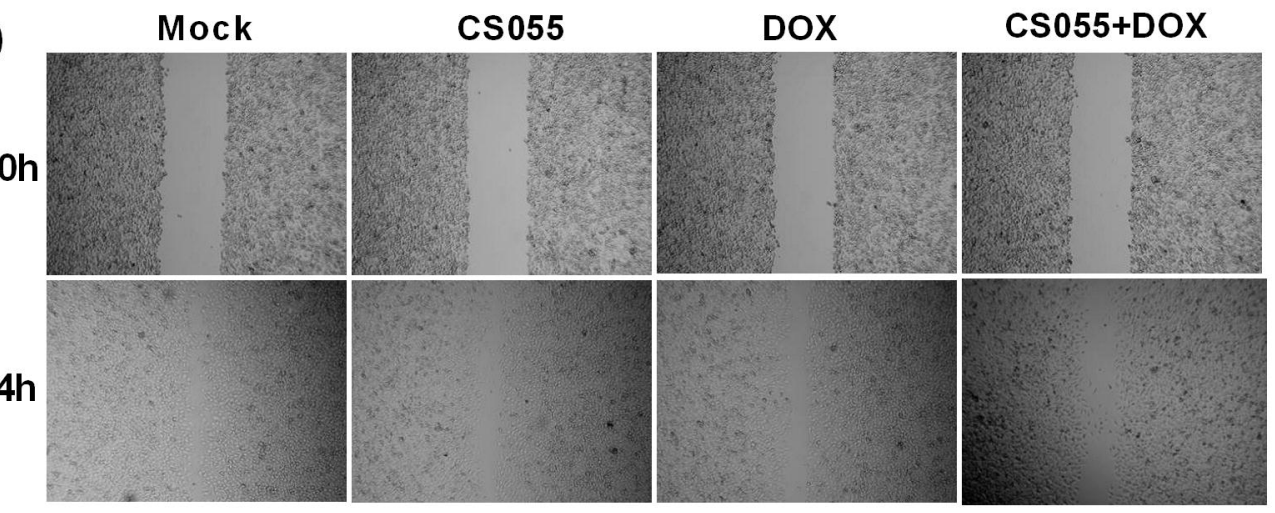

HTh74

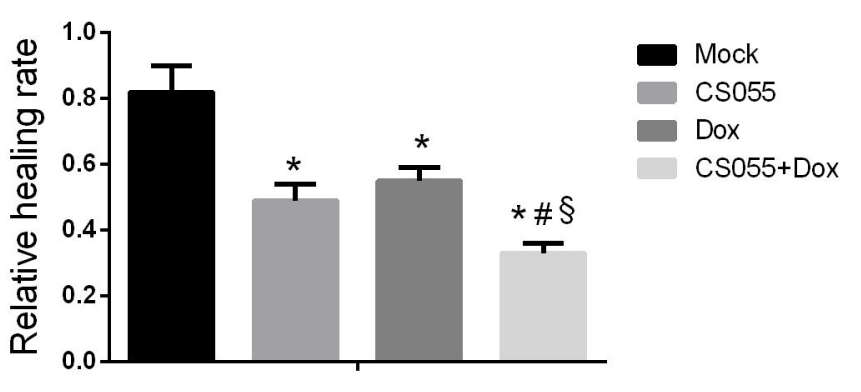


A

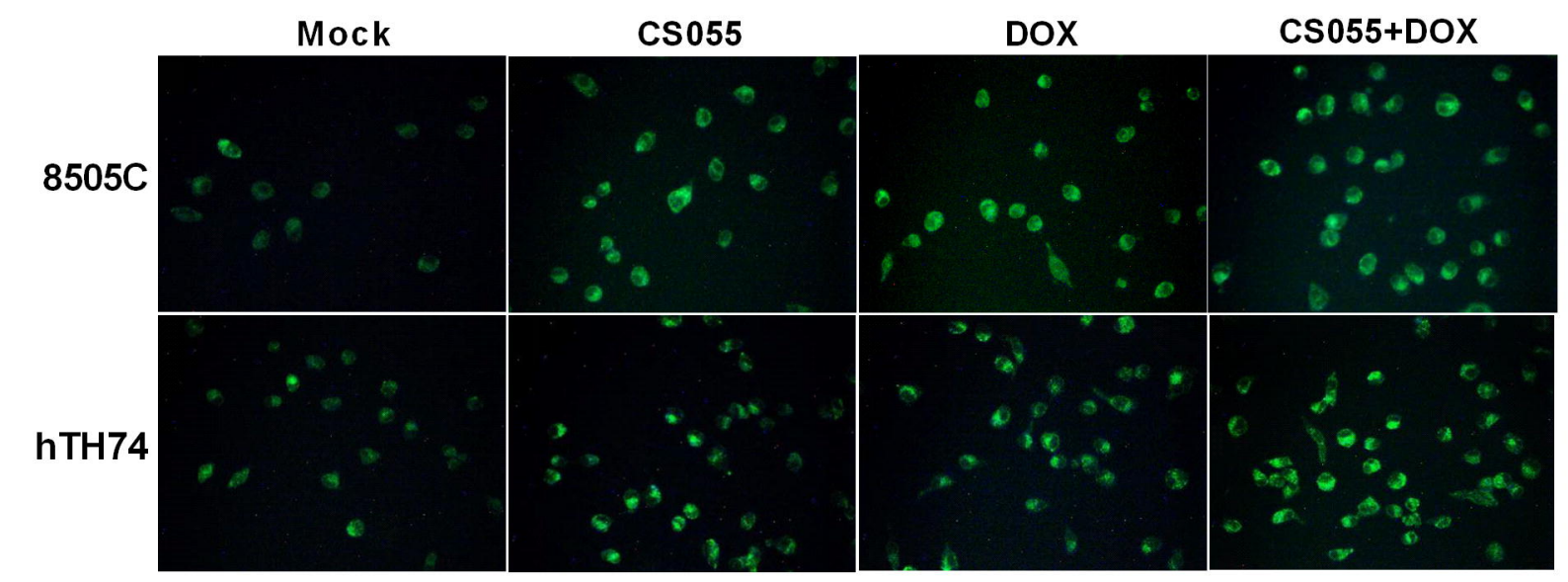

B
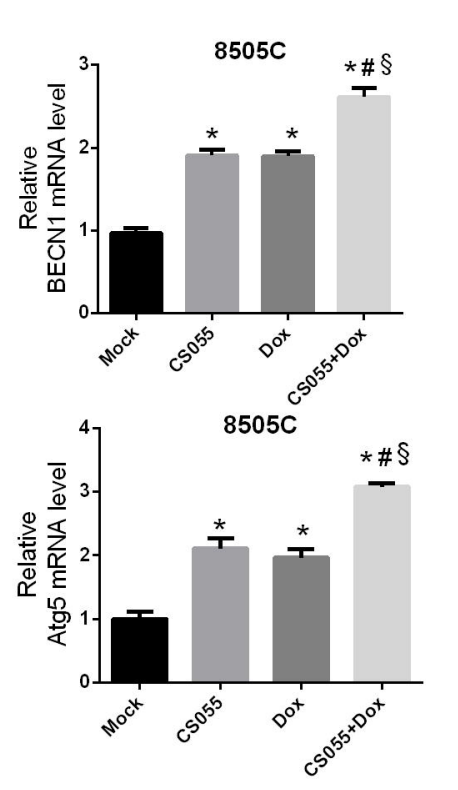
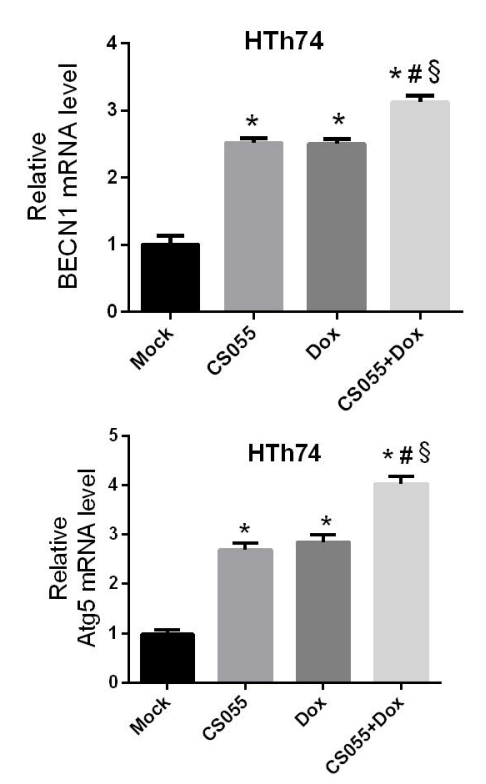

C
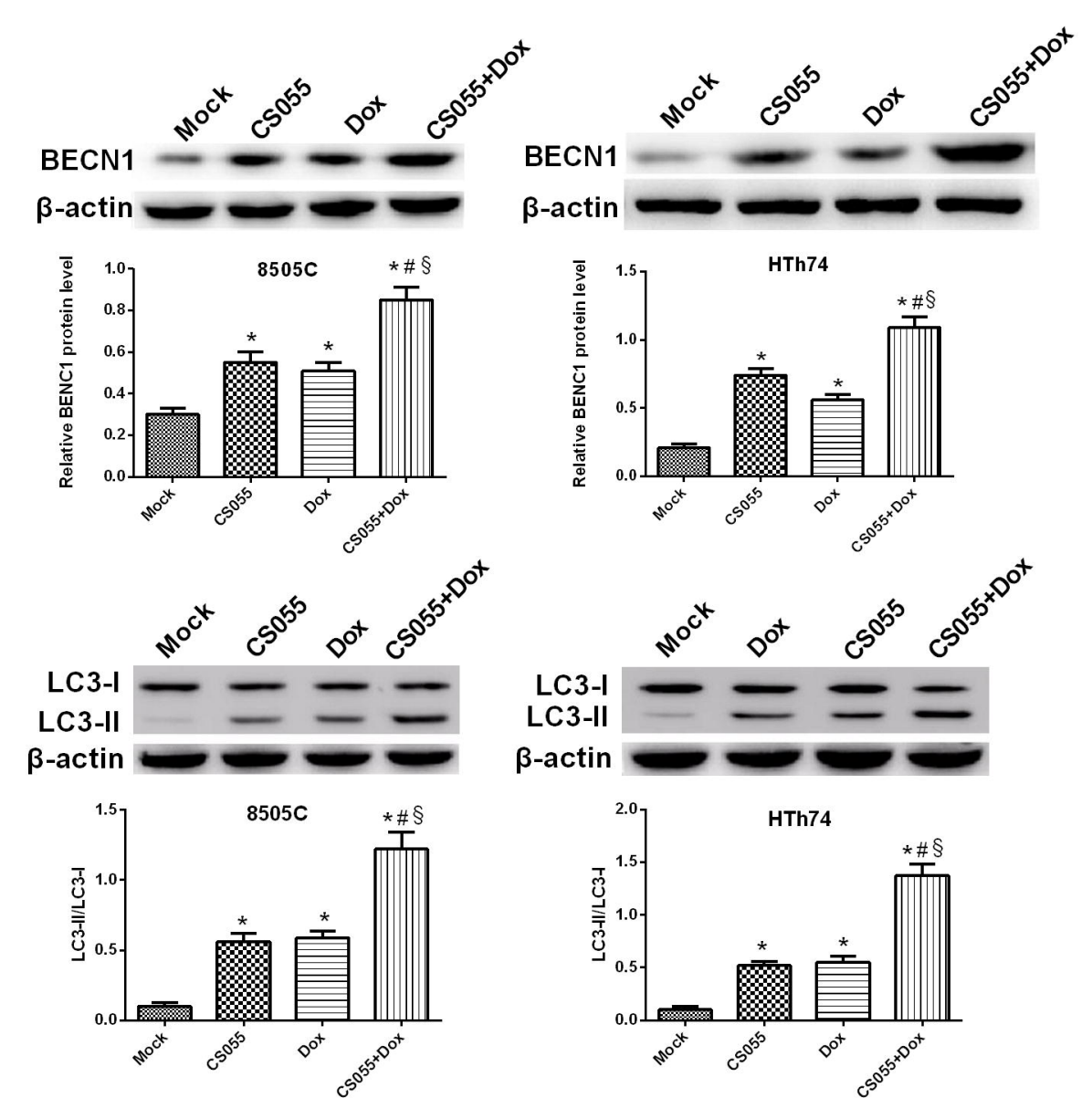
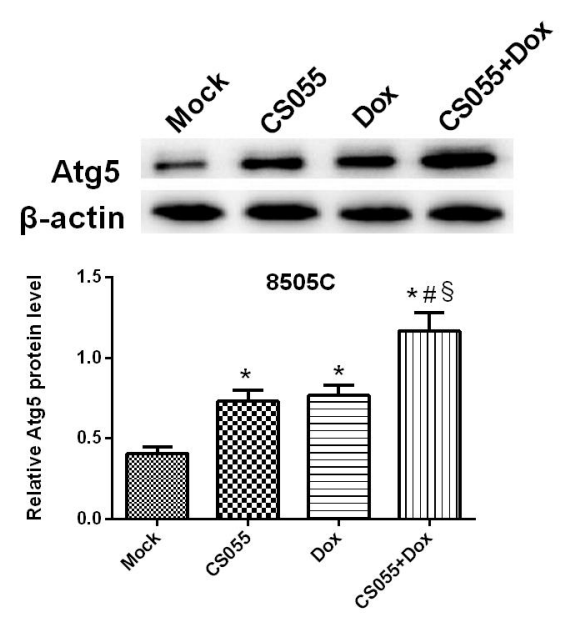
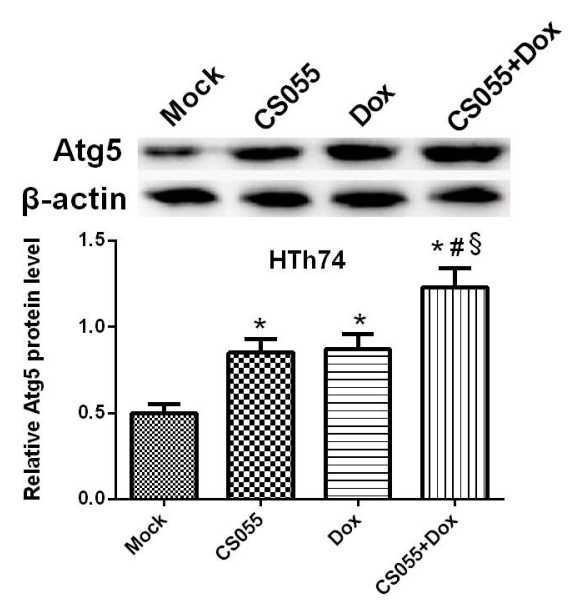
A

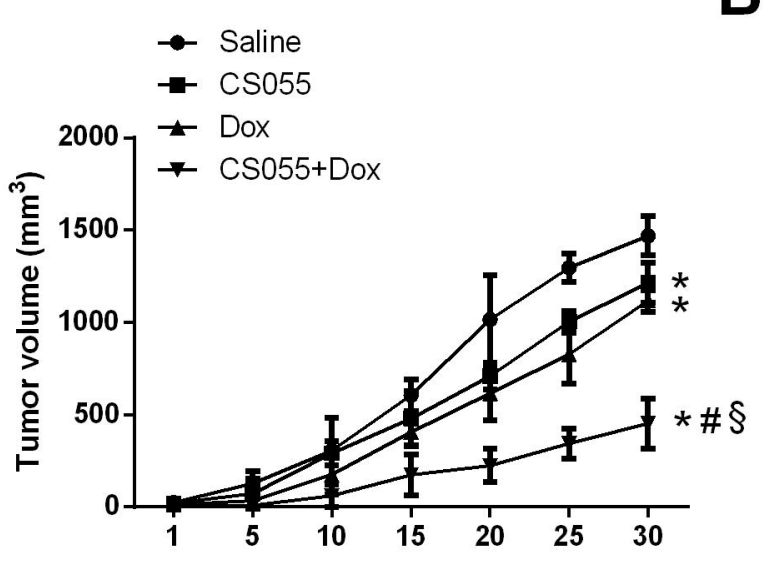

B
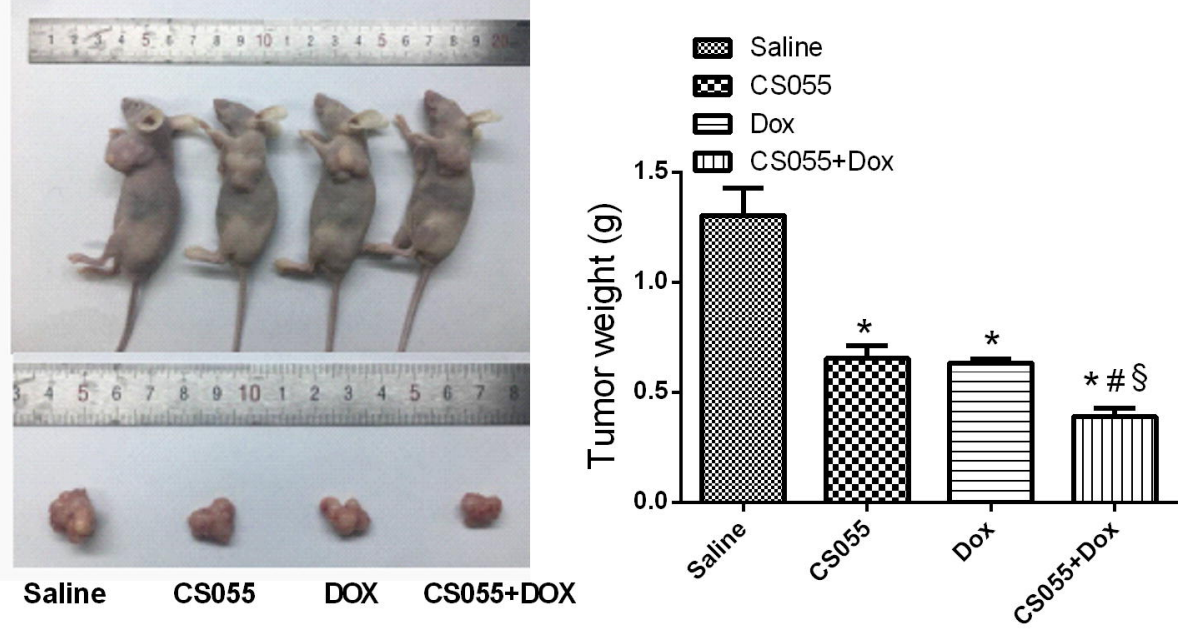

C
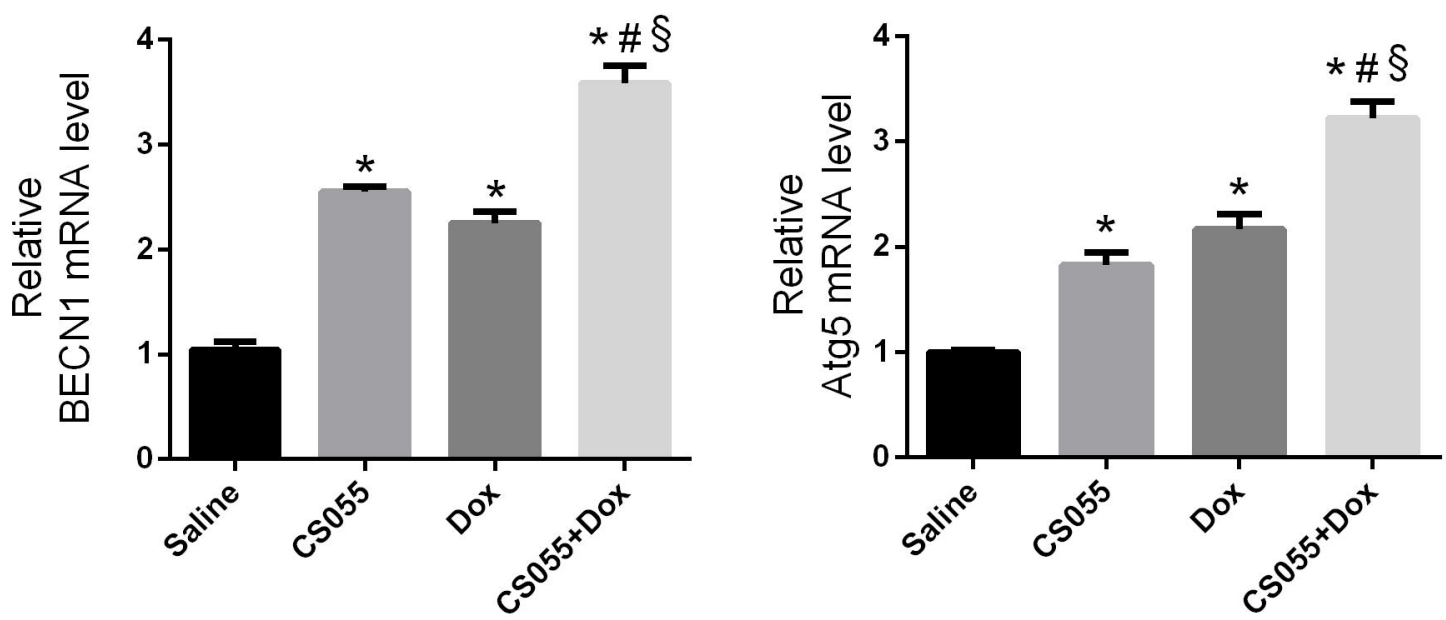

D

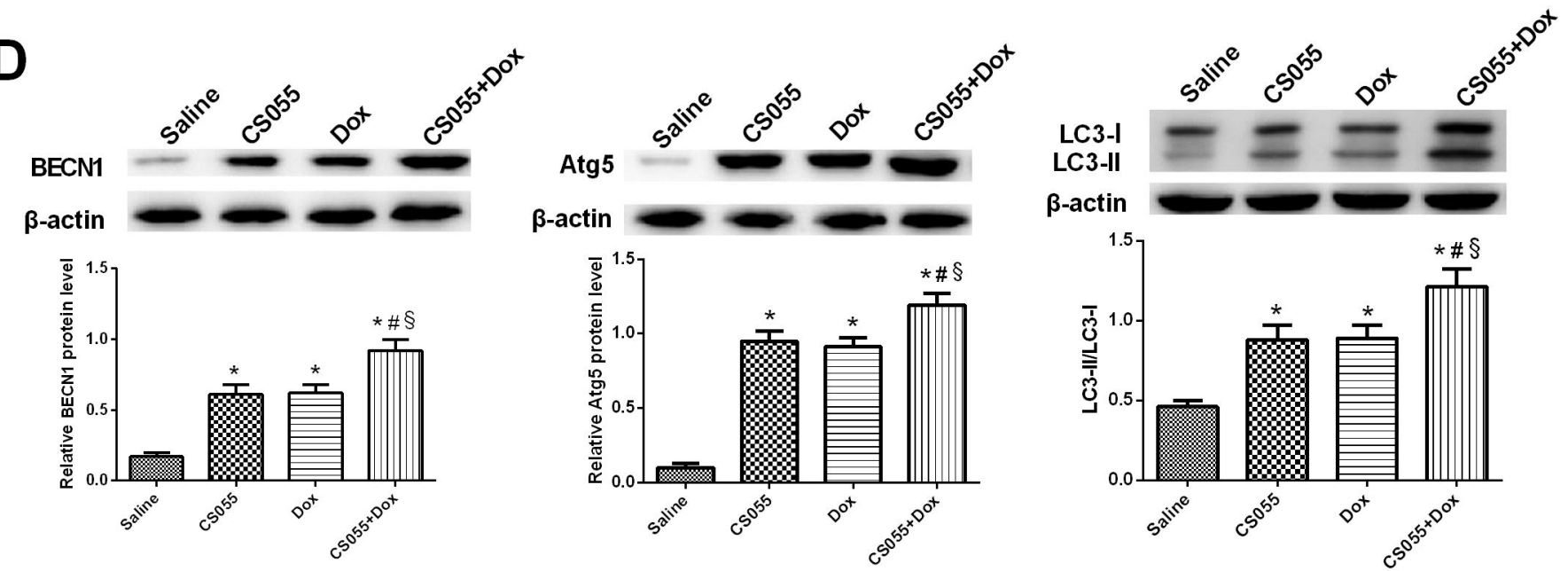


A

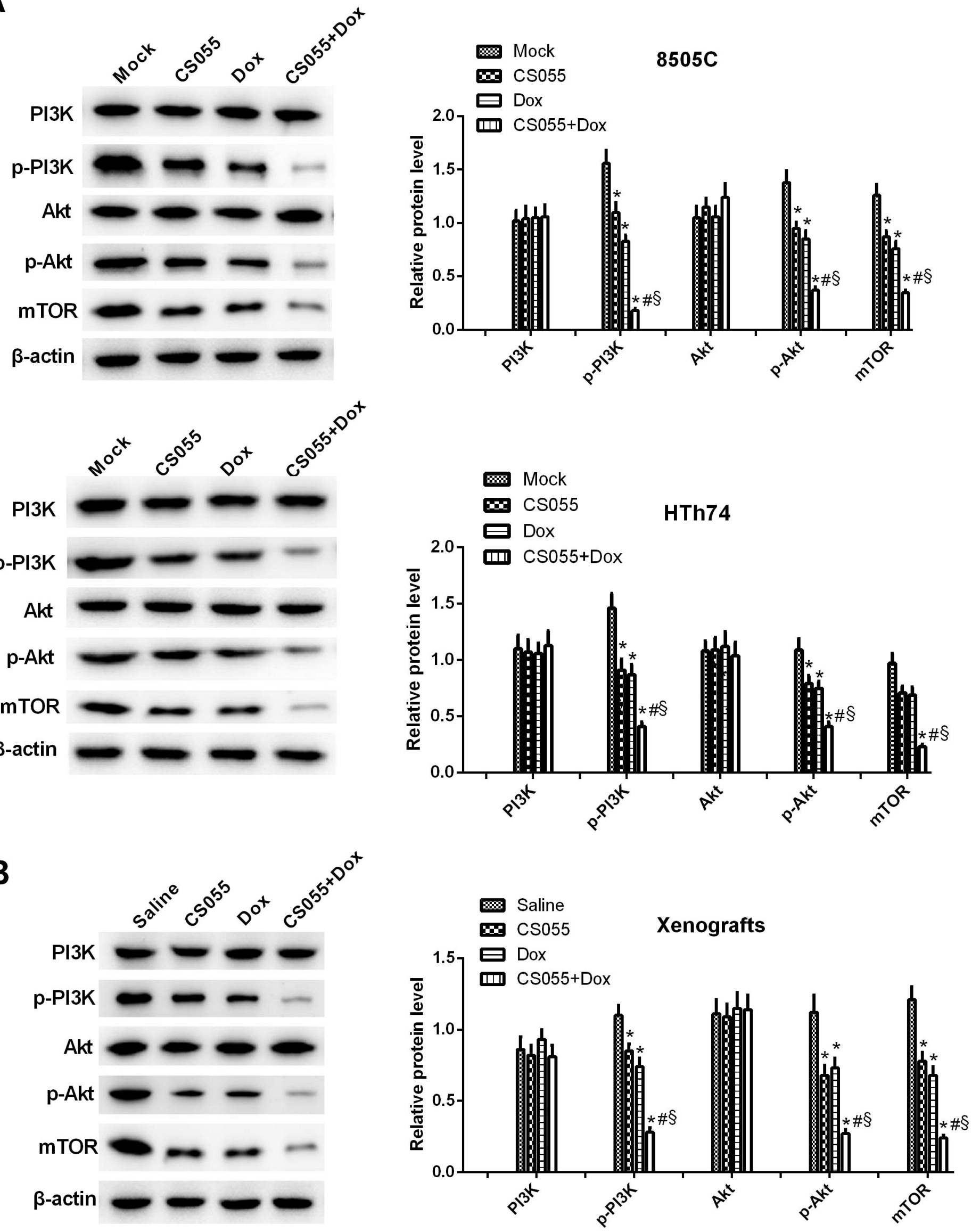

